NOTICIAS Y COMENTARIOS 


\title{
LA CONSERVACIÓN DE LOS CAMINOS ALICANTINOS EN EL SIGLO XIX
}

\author{
Jesús Rafael de Vera Ferre
}

\section{RESUMEN}

La conservación de las carreteras de Alicante en el siglo XIX viene caracterizada por su falta de continuidad, la escasez de presupuesto, las dificultades tecnológicas y el efecto de la climatología y el relieve.

\begin{abstract}
The maintenace of Alicante's roads in XIX centurys qualified by the lack of continuit, shortage of budgets, the technological diffieculties and the efect of climate and orography.
\end{abstract}

\section{Condiciones básicas de la conservación de la red en el Ochocientos en Alicante}

Si la preocupación por la construcción de obras públicas camineras es un afán constante a lo largo de la centuria, al menos desde el segundo tercio de la misma, la conservación de la red sufrió todos los avatares inherentes a la falta de continuidad en la labor, ausencia de una voluntad clara de llevarla a cabo y escasez constante de fondos económicos en que basarla.

En este sentido, diversos factores caracterizan la labor de conservación de las carreteras y caminos del Sur del País Valenciano a lo largo del Ochocientos:

1. La influencia del relieve, con la existencia de zonas morfoestructurales difíciles que gravan de forma extraordinaria los costos económicos de las reparaciones, al tiempo que las dificultan en los meses invernales, junto a otras áreas llanas, pero con frecuencia fácilmente inundables, a la par que la utilización de trazados que, paradójicamente, por estar muy adaptados a los cursos de los ríos, ramblas y rieras sufren desbordamientos y encharcamientos y reciben acarreos de materiales provinientes de la erosión, lo que deviene en constantes destrozos de las vías.

2. Las condiciones climáticas de la provincia que alternan períodos de sequía prolongados con lluvias copiosas y, a menudo, de alta intensidad horaria que destrozan brutalmente las infraestructuras y acarrean depósitos y restos vegetales. 
3. Las constantes penurias de las haciendas públicas para dotar de fondos a la tarea de conservación y que hizo exclamar a Ponz a finales del siglo anterior: «España ha estado con razón desacreditadísima por la incuria rematada de los caminos» ${ }^{1}$.

4. Los limites tecnológicos que, entre otras cosas, requieren un ingente número de peones sin cualificar; la penuria de los materiales empleados y la poca solidez de los firmes.

5. La poca productividad de las cuadrillas de obras por falta de una organización moderna de las mismas y de sus modos de transporte.

6. Los intereses de las clases mercantiles y de la aristocracia agraria que presionan constantemente, y no siempre con éxito, para que se mejore la conservación viaria como una garantía de salida y entrada de materias primas y productos, afianzando, de esta forma, la circulación comercial y, por ende, sus ganancias.

7. Las estrategias de los organismos públicos responsables de la red viaria centradas más en generar una malla de nuevo cuño, ya que no existe apenas, a comienzos de la centuria, una articulación del territorio ${ }^{2}$, que en la mera conservación de las obras realizadas $^{3}$.

8. La necesidad de generar empleo en el sector para poder paliar el exceso de mano de obra en las tierras agrícolas de secano.

\section{Impactos negativos para la conservación de la red}

Relieves agrestes en la mitad septentrional de la provincia y régimen pluviométrico mediterráneo en todo el territorio han supuesto siempre una asociación penosa para el estado de conservación de la red viaria alicantina. Decía Madoz al respecto de la zona «que conocida su general aspereza, los barrancos y cortaduras que por todas partes la cruzan, fácil es conocer que aquellos (los caminos) deben ser pocos y malos» ${ }^{4}$. La escorrentía de las aguas devastaban los escasos firmes de macadam y los frecuentes pisos de tierra y arruinaban puentes y pontones ${ }^{5}$, a la par que se producían desplomes en las áreas montañosas que se resolvían en aislamientos prolongados y daños a los carruajes por la mezcla de acarreos de piedra, restos de ramas, encharcamientos y barro.

La zona más castigada era siempre la mitad septentrional en la que se producía un abarrancamiento progresivo de las vertientes por la ausencia de un tratamiento específico de plantaciones vegetales que impidieran los deslizamientos y desprendimientos sobre las carreteras. Evidentemente, los costes elevados de obras civiles de defensa contra las crecidas y la erosión excedían totalmente a las posibilidades presupuestarias de los organismos competentes que, en muchos casos, no eran ni siquiera capaces de finalizar las reparaciones por falta de fondos ${ }^{6}$.

1 PONZ, S.: Viage de España. Madrid, $3^{\text {a }}$ ed., Imprenta Viuda de Ibarra, 1789, t. I, p. 4.

2 DE VERA FERRE, J. R.: La formación de la red de carreteras de la provincia de Alicante. 1833-1982. Alicante, Universidad de Alicante e Instituto de Cultura Juan Gil Albert, 1992.

3 NÚÑ̃Z DE PRADO, J.: De las Obras Públicas en España. Madrid, 1869, pp. 249 y ss.

4 La Voz de Jijona, 26 de enero de 1879.

5 El puente sobre el río Segura tuvo que ser reparado en varias ocasiones y la carretera del Barranco de la Batalla reconstruida en diversos momentos según se iba creando. ARCHIVO DIPUTACIÓN PROVINCIAL. SEC. II, leg. 89 y 54 respectivamente.

6 A.D.P. Memoria presentada por la Comisión Permanente a la Excma. Diputación Provincial. Alicante, manuscrita, 1 de abril de 1876. 
Por otro lado, la conservación se hace sumamente costosa porque los trazados no poseen condiciones adecuadas para su duración en buenas condiciones durante mucho tiempo. Así, por ejemplo, son prácticamente desconocidos canales de desagües suficientes, zanjas, excavaciones con finalidad absorbente, correcciones de pendientes que tengan totalmente resuelto de forma eficaz el drenaje y puentes y pontones con suficiente luz para dar salida a una escorrentía excepcional, al tiempo que escasean los elementos de soporte de deslizamiento de las vertientes. La inadaptación de la malla viaria al territorio en el que se instala queda también de manifiesto en el taponamiento de los conos de deyección de las ramblas por la intrusión de elementos constructivos.

Existe una auténtica obsesión en los políticos de la centuria por llevar a cabo las obras viarias con un costo muy escaso en materiales lo que conlleva un intento de transformar al mínimo la naturaleza, evitando, así, las costosas intervenciones de la ingeniería, lo que incide en la posterior conservación de lo realizado. Esta filosofía genera, por ejemplo, en la zona Norte de la provincia, que se aprovecharan para el trazado de las carreteras las cuencas vertientes de pequeños valles y los barrancos de encajamiento vertical. Se utilizan de esta forma unas redes de fractura cuyas vertientes episódicamente poseen circulación hídrica, pero que, en momentos de fuertes lluvias, sufren una intensa erosión y el arrastre de derrubios que producen la ruptura y escombramiento de los pavimentos.

También se producen con el trazado de la red, al buscar este las más favorables áreas de las cuencas vertientes, basadas en las zonas de menor desnivel en relación al perfil transversal y longitudinal del valle, un cambio no previsto del rumbo de las aguas que provoca serios problemas al mantenimiento.

\section{Las fases temporales en el mantenimiento de los caminos lucentinos en el Ochocien- tos}

La falta de continuidad en la conservación de la red, cuando no la ausencia total de obras en algunos períodos de la centuria, supone, junto a la escasa articulación y densidad de la malla circulatoria, un lastre serio que impide tanto la necesaria fluidez en el transporte de personas y mercancías, como constantes retrasos en la recepción de estas últimas y un encarecimiento de las mismas ${ }^{7}$.

En el primer tercio del siglo, la ausencia total de cualquier obra de conservación de la red es el justo contrapunto a un desinterés manifiesto por mejorar los maltrechos caminos. Solamente, en el periodo isabelino, empieza a tomar cuerpo una cierta preocupación por este tipo de obras, al calor de las inversiones que se realizan para empezar a diseñar una primera malla circulatoria. De todas formas, en general, salvo excepciones, las bregas que se emprenden son muy limitadas, centradas fundamentalmente en ligeras reparaciones o parcheos y la reconstrucción de algún puente. A veces, incluso, se utiliza la conservación como una forma episódica de celebrar algún acontecimiento. Es paradigmática en este sentido la orden dada por el Conde de Santa Clara de un arreglo general de las sendas con motivo de su toma de posesión como gobernador de Alicante $^{8}$.

Si durante los años cuarenta, el único arreglo destacado es la reparación general de la importante ruta de Alicante a Almansa ${ }^{9}$, en la década siguiente se hace algo más continuada la política de conservación, al calor de la existencia de una relativa mayor densidad de

7 MARTÍN SÁNCHEZ, M. de: Memoria sobre los estados de los caminos vecinales de la provincia de Alicante. Alicante, Imprenta de las Viuda de J. J. Carratalá, 1862.

8 RAMOS, V.: Historia de la provincia de Alicante y de su capital. Alicante, Diputación Provincial, 1971, t. I, p. 386.

9 Gaceta de Madrid del 20 de junio de 1847. 
la red, de las presiones de los prohombres ligados a los negocios comerciales y agrarios, que vivieron un buen período económico desde 1857 a 1867, y de la aparición de la Ley de 28 de abril de 1849 que garantizaba una mayor inversión y marco legal para estos menesteres ${ }^{10}$.

Una cierta aceleración en el tema se vive en Alicante durante el sexenio revolucionario cifrándose las principales actuaciones en la reparación de los caminos de Monóvar hacia el altiplano yeclano ${ }^{11}$ y de Alcoy a Bañeres ${ }^{12}$, aparte de pequeñas obras de parcheo en otras vías $^{13}$.

La época de la Restauración supone una pequeña mejora en la reparación de los caminos. En el año 1888 se inician las obras de arreglo de la carreteras de Alicante a Játiva y de Cocentaina a Denia ${ }^{14}$.

En el resto del período, entre otras muchas obras de conservación ${ }^{15}$, se abordan las de Pego a Oliva, Gata a Jávea, Alcoy a Bañeres, Alicante a Agost y de la que conduce de Elche a Dolores lo que supuso una mejora de la fluidez circulatoria provincial $^{16}$.

10 Revista de Obras Públicas. Suplemento sobre legislación de Obras Públicas. $1^{\text {a }}$ serie, t. III. Madrid, 1856, pp. 147 y ss.

11 A.D.P. Secc.V. y O., leg. 213.

12 A.D.P. Secc.V. y O., leg. 38 y 87.

13 A.D.P. Secc.V. y O., leg. 89.

14 OBRAS PÚBLICAS: Memoria sobre el estado de las carreteras en el año 1888. Madrid, Tipografía de Ricardo Álvarez, 1889.

15 A.D.P.Secc.V.y O., leg. 166

16 A.D.P.Secc. V. y O., leg. 89, 99 y 208. 